duration upon discrimination learning human subjects. Journal of Experimental Psychology, 1965, 2, 528-533.

HARLOW, H. F., \& BROMER, J. A. A test-apparatus for monkeys. Psychological Record, 19.38, 2, 434-436.

LeVERE, T. E. The effects of pre- and post-response stimulus sampling on discrimination performance. In D. Starck, R. Schneider, \& H. J. Kuhn (Eds.) Progress in primatology. Stuttgart, Germany: Gustav Fischer Verlag, 1967. Pp. 310-315.

LeVERE, T. E. Cue size and learning set performance with $S-R$ induced sampling biases eliminated. Journal of Physiological Psychology, 1968a. $65,362-365$.

LeVERE, T. E. The failure of stimulus-reinforcement spatial discontiguity to influence performance under optimal conditions of stimulus sampling. Psychonomic Science, 1968b, 11, 179-180.

MEYER, D. R., TREICHLER, F. R., \& MEYER, P. M. Discrete-trial training techniques and stimulus variables. In A. M. Schrier, H. F. Harlow, \& F. Stollnitz (Eds.), Behavior of nonhuman primates. Vol. 1 . New York: Academic Press, 1965. Pp. 1-49.

OTTESON, M. I., SHERIDAN, C. L., \& MEYER, D. R. Effects of stimulus-response isolation on primate pattern discrimination learning.
Journal of Comparative \& Phy siological Psychology. 1962, 55, 935-938 SCHUCK, J. R. Pattern discrimination and visual sampling in the monkes Journal of Comparative \& Physiological Psychology, 1960. 53, 251-255 SHERIDAN, C. L., HORLL, J. A.. \& MIYYR. D. R. lificets of response-induced stimulus change on primate discrimination learning. Journal of Comparative 7 Physiological Psychology, 1962, 55 . 511-514.

SPENCE, K. W. Analysis of the formation of visual discrimination habits in chimpanzee. Journal of Comparative Psychology, 1967, 23, 77-100.

\section{NOTES}

1. This research was supported by Grant MH 14457-02 from the National Institute of Mental Health.

2. The authors wish to express thanks to $C$. A. LeVere for her help in analysis and preparation of this report.

3. Flow diagrams and preliminary software for the Linc computer are available on request from the authors.

4. Due to the flexibility of electromechanical relay and timer pancls. detailed wiring diagrams are not presented. The authors arrangement is available upon request.

\title{
The effect of pressurized air in establishing discriminative response suppression in stump-tailed macaques'
}

\author{
JOEL KAPLAN and CHARLES REBERT, STANFORD \\ RESEARCH INSTITUTE, Menlo Park, California 94025
}

Pressurized air was repeatedly associated with one of two frequencies of flashing light during performance of a VI $30-\mathrm{sec}$ positive reinforcement schedule by stump-tailed monkeys. As revealed by the relative suppression of bar presses to each of the two visual stimuli, the Ss learned to discriminate between the different flicker frequencies. However, they also showed signs of adapting to the airblast during the course of training, and its location had to be changed in order to maintain discriminative suppression.

Pressurized air (PA) has been shown to be an effective aversive stimulus in modifying the behavior of rats (Kaplan, 1968; Ray, 1966a, b), cats (Ray, 1966c), and squirrel monkeys (Polidora \& Boyer, 1967). In the few experiments in which PA was used as an aversive stimulus, its effect was measured mainly in "active" avoidance tasks. Polidora and Boyer (1967) found that acquisition and extinction of shuttle-avoidance behavior by squirrel monkeys were more rapid with PA than with electric foot shock. They concluded that PA facilitated avoidance learning because it produced less disruptive effects than shock did early in training. However, the fact that the extinction of the response to PA was also more rapid suggests that PA was actually less aversive than foot shock and that it did not produce as strong a conditioned emotional response. Therefore, it might be expected that Ss would adapt to the repeated presentation of unavoidable PA, in dicating that PA would not be an effective aversive stimulus in learning paradigms that involve repeated association of conditioned and unconditioned stimuli, e.g., conditioned suppression paradigm. In the present experiment, PA was repeatedly associated with one of two visual stimuli, and the acquisition and extinction of discrimination performance was determined by the relative suppression of responses in the presence of each stimulus. macaques (Macaca speciosa), weighing $6.7 \mathrm{~kg}$, were trained to bar-press for $0.5 \mathrm{cc}$ of grape juice on a VI 30-sec reinforcement schedule while restrained in a primate chair. After their response rates stabilized, a strobe light, driven by a Grass Model PS-2 photostimulator, was used to present 10 -sec trials at either 15 flashes/sec (CS-15) or 60 flashes/sec (CS-60). Ten trials at each frequency were randomly ordered and presented during each daily session, with an average intertrial interval of $2 \mathrm{~min}$. After the Ss habituated to the visual stimuli (determined by the lack of suppression of bar presses during visual stimulation), a 1-sec period of PA at $50 \mathrm{lb} / \mathrm{in}^{2}{ }^{2}$ immediately followed each CS-15 trial. The 1-sec airblast was delivered through a 15-ga hypodermic needle located 1 in. to the side of the $S$ 's head and aimed at the area behind the right ear. As the Ss adapted to the PA during the course of discrimination training, the hypodermic needle was moved to a different location $2 \mathrm{in}$. in front of the $S$ and aimed at the nose. The relative amount of discrimination between CS-15 and CS-60 was measured by comparing the average number of bar presses during these trials with the number of presses during the $10-\mathrm{sec}$ interval immediately preceding the onset of CS (pre-CS). Since bar-pressing rates during the pie-CS-15 and pre-CS-60 intervals were not different, the average number of pre-CS bar presses was obtained by combining both pre-CS conditions. Discrimination training was terminated when the number of bar presses during CS. 60 reached $90 \%$ of those made during the pre-CS interval in three successive sessions. Four extinction sessions were then presented in which the airblast was removed from the CS-15 trials. CS trials, intertrial intervals, positive reinforcement, and airblasts were controlled automatically with appropriate timers, solenoids, and pulse generators. A Grass Model 5 polygraph was used to record bar presses and pre-CS and $\mathrm{CS}$ intervals during each session.

\section{RESULTS AND DISCUSSION}

Both Ss learned to discriminate between the 15/sec flashing 


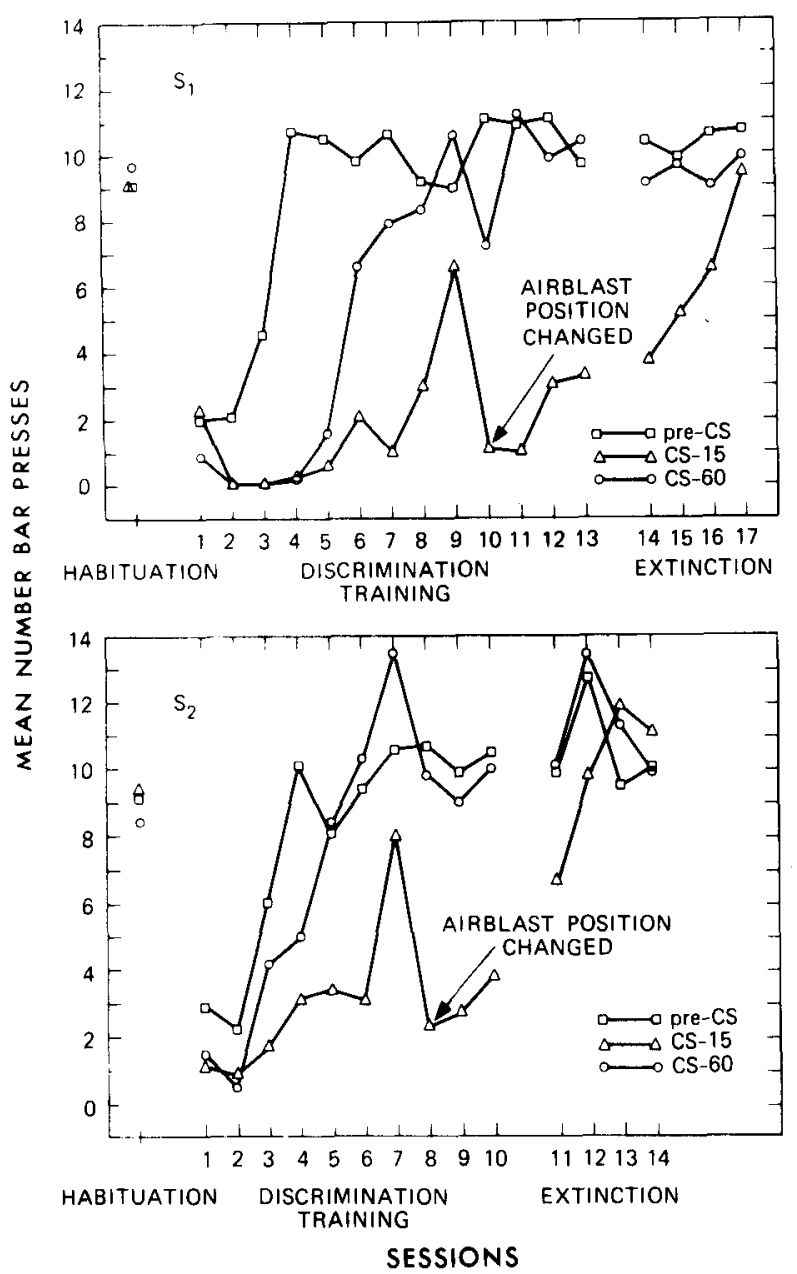

Fig. 1. Changes in bar-pressing performance during training and extinction of a discriminative response suppression task. During training a 1-sec airblast followed a visual stimulus of 15 flashes/sec (CS-15) but not one of 60 flashes/sec (CS-60). The pre-CS period was of the same duration as the CS periods and immediately preceded CS onset. light that was associated with airblast and the $60 / \mathrm{sec}$ flashing light that was not, as shown by the significant difference in suppression of bar presses between these two conditions in the last three training sessions ( $t$ test, $p<.001$ ), and the lack of difference between the CS-60 and pre-CS conditions in these same sessions (Fig. 1). However, each S showed definite signs of adapting to the airblast during the course of training. Suppression of bar presses during CS-15 was greatly attenuated in Session 7 for one animal and in Session 9 for the other. When the position of the tubing through which PA was delivered was then moved to a different location, bar-pressing suppression during CS-15 recurred. Complete extinction of response suppression followed removal of airblast from CS-15 trials.

These results show that PA can be used as an effective aversive stimulus in learning situations where conditioned and unconditioned stimuli are repeatedly paired, although it is possible that learning will be masked by adaptation to the PA. In the present experiment, the $S$ s began to show poor discrimination behavior as they adapted to the airblast aimed at the side of the head. However, they displayed successful discrimination performance as soon as the airblast was changed to a different location on the face. Whether or not the Ss would have fully adapted to this new location cannot be answered by the present experiment, al though they did show somewhat less suppression during CS-15 trials on the last few training sessions (see Fig. 1).

\section{REFERENCES}

KAPLAN, J. Approach and inhibitory reactions in rats after bilateral hippocampal damage. Journal of Comparative \& Physiological Psychology, 1968, 65, 274-281.

POLIDORA, V. J., \& BOYER, W. N. Avoidance learning by squirrel monkeys: Measures and motivators. Psychonomic Science, 1967, 7, 175-176.

RAY, A. J., JR. Shuttle avoidance: Rapid acquisition by rats to a pressurized air unconditioned stimulus. Psychonomic Science, 1966a, 5, 29-30.

RAY, A. J., JR. Nonincremental shuttle-avoidance acquisition to pressurized air US. Psychonomic Science, 1966b, 5, 433-434.

RAY, A. J., JR. Shuttle avoidance: An apparatus for cats utilizing an air-blast unconditioned stimulus. Journal of Genetic Psychology, 1966c, 109-131.

\section{NOTE}

1. This research was supported by Grant NB 07916 from the National Institutes of Health to Lawrence R. Pinneo. 